\title{
UMA TRAMA DE FALAS E SILÊNCIOS: CAMINHOS DE UMA POLÍTICA PÚBLICA DE LOGÍSTICA REVERSA EM SOLO GAÚCHO
}

Caroline Roberta Todeschini Lazzarotto ${ }^{1}$

Luciele Nardi Comunello ${ }^{2}$

Resumo: No ano de 2017, a Logística Reversa (LR) das Lâmpadas Fluorescentes (LF) posicionava-se como um desafio no Município de Bento Gonçalves. Imerso nesse cenário, o presente trabalho objetiva apresentar os caminhos percorridos e revelar os actantes e as vozes ou silêncios atuantes na efetivação da Política Pública (PP) que trata sobre as LF no referido município. A metodologia qualitativa partiu de uma inspiração etnográfica. $O$ processo esteve permeado por iniciativas nas esferas municipais, estaduais e federais. $O$ engajamento popular, promovido por um sólido programa de Educação Ambiental, além de ações por parte da municipalidade parecem ter sido os grandes motivadores da implantação efetiva da PP analisada.

Palavras-chave: Lâmpadas Fluorescentes; Logística Reversa; Educação Ambiental; Bento Gonçalves; Políticas Públicas.

Abstract: In 2017, the Reverse Logistics (LR) of Fluorescent Lamps (LF) positioned itself as a challenge in the Municipality of Bento Gonçalves. Immersed in this scenario, the present work aims to present the paths taken and reveal the actors and the voices or silences acting in the effectiveness of the Public Policy (PP) that deals with the LF in that municipality. The qualitative methodology came from an ethnographic inspiration. The accompanied process was permeated by initiatives at the municipal and state levels and finally contemplated nationally by a sectoral agreement. In addition to popular engagement, promoted by a solid Environmental Education program, actions by the municipality seem to have been the main motivators for the effective implementation of the analyzed PP.

Keywords: Fluorescent Lamps; Reverse Logistic; Environmental Education; Bento Gonçalves; Public Policies.

1 Universidade Estadual do Rio Grande do Sul. E-mail: caroltodeschini@gmail.com.

2 Universidade Estadual do Rio Grande do Sul. E-mail: luciele-comunello@uergs.edu.br. 


\section{Introdução}

O presente artigo é parte de uma dissertação de mestrado em que se investigou, através de pesquisa participante, a implementação da Política Pública de Logística Reversa de Lâmpadas Fluorescentes no município de Bento Gonçalves. O olhar da pesquisa partiu da experiência de uma profissional atuante em seu meio de estudo, sendo efetiva do Setor de Educação Ambiental da Secretaria de Meio Ambiente Local, ao perceber a problemática em relação ao descarte e Logística Reversa de bens de consumo ordinários como uma das maiores demandas do setor. Apesar do papel orientador deste setor junto à comunidade, no sentido de promover o bom descarte dos resíduos domésticos, por meio de diálogos tanto com a comunidade quanto com os comerciantes, constatou-se que o resíduo doméstico não se limita ao que é destinado à reciclagem, ao que pode ser compostado e aos rejeitos que tem o Aterro Sanitário como destino.

Os resíduos com potencial contaminante (como pilhas, latas de inseticida e lâmpadas fluorescentes) surgem como grandes incógnitas para boa destinação na fonte geradora, tendo em vista a casa dos mais de cem mil habitantes do município para o dimensionamento da problemática. Foi a partir da vivência profissional diante dessa demanda que surgiu o interesse pela elaboração da pesquisa que originou esse artigo. Estimamos que possa promover um exercício em que espreite o conjunto de atores - humanos e não humanos - que compõem um dos possíveis universos da Logística Reversa de Lâmpadas Fluorescentes enquanto Política Pública, propondo pensá-la a partir da proposta de Bruno Latour (2012), com sua teoria do Ator-Rede, ao compreender a duração de processos sociais a partir do rastreamento das conexões daquilo que se agrega, em associações de elementos heterogêneos - "de ligações químicas e vínculos jurídicos, de forças atômicas a corporações, de organismos fisiológicos a partidos políticos" (LATOUR, 2012, p.23).

Como objetivo geral deste artigo buscou-se dar visibilidade e trazer à tona as vozes e os silêncios dos actantes. Com isso, objetivamos exibir condutas e elementos envolvidos em uma rede sociotécnica - o processo da efetivação da Política Pública de Logística Reversa de Lâmpadas Fluorescentes no município de Bento Gonçalves.

Iniciamos trazendo um pouco sobre a metodologia adotada, elucidando conceitos eleitos para realizar essa abordagem sobre o assunto e expondo uma parte da Legislação pertinente às Lâmpadas e ao mercúrio (elementos que compõem e atuam nesta rede) para complementar o entendimento acerca da necessidade de uma LR das mesmas.

No decorrer deste artigo procuramos compartilhar questões referentes à toxicidade do mercúrio e assim desvelar, conforme já apresentado, a rede que envolve a Política Pública de Logística Reversa das Lâmpadas Fluorescentes no município de Bento Gonçalves. Propõe-se seguir e observar as conexões entre as diferentes perspectivas sobre a LR das LF e as Políticas Públicas que as conduzem, através da das conversas entrevistas realizadas com diferentes 
setores que, ora tencionam, ora buscam soluções para a efetivação desta Logística Reversa. Igualmente importante neste cenário é abrir um diálogo com o silêncio, que é por muitas vezes atribuído à Lâmpada.

Nas considerações finais, propomos algumas possíveis reflexões (in)conclusivas sobre o assunto, na medida em que ele não se esgota. As reflexões levantadas possuem o potencial de ser adustível para ponderações acerca do ambiente que habitamos em conexão/associação com uma gama infinita de atores ou atuantes humanos e não humanos.

\section{Metodologia: seguindo associações}

A opção metodológica foi pela abordagem qualitativa, ao realizar a imersão no campo, através de pesquisa participante. Quanto ao corte temporal, a pesquisa realizou-se entre os meses anteriores à Audiência Pública que regulamenta Lei Municipal (Lei no 4.418/08), ocorrida em 17 de novembro de 2017, seguindo seus desdobramentos até dezembro de 2019.

Houve a aproximação pesquisador-participante, expressa por Gil (2008), com a pesquisa de campo ativa pelo pesquisador em seu meio. A observação e registro dos fenômenos históricos e a evidenciação dos conflitos presentes na efetivação da Logística Reversa foram presenças constantes.

Entre as particularidades da inserção da pesquisa neste campo, bem como o lugar ocupado pela pesquisadora no cenário pesquisado, trouxeram consequências ambíguas, que devem ser consideradas na apreciação deste trabalho. Sobre essa intensa imersão, (GIL, 2010:41) pontua que, "como o pesquisador apresenta maior nível de participação, torna-se maior a probabilidade de os sujeitos oferecerem respostas mais confiáveis".

Seguimos actantes e práticas do processo, na medida em que havia um engajamento prévio no contexto da pesquisa. Ao mesmo tempo, sustentou-se a proposta de mapear os caminhos efetuados e revelar actantes influentes para implementação da LR. Foram realizadas entrevistas ${ }^{3}$, observações e conversas com registro em diário de campo com perguntas abertas, em conversas de caráter descerimonioso. Neste artigo são trazidas parte das vozes importantes nessa rede, bem como as Lâmpadas Fluorescentes (LF) com seu aparente silêncio.

3 Foram tomados como procedimentos éticos em pesquisa o acordado na Resolução do Conselho Nacional de Saúde 510/2016. Foi feito o uso do Termo de Consentimento Livre e Esclarecido (TCLE), com a explicitação do consentimento do participante. Também foi empregado o amparo promovido pelo precedente aberto nesta resolução - a anuência concedida verbalmente. Embora a maior parte dos registros tenha sido caracterizada por conversas informais registradas em diário de campo, com consentimento dos envolvidos, inclusive para explicitação de nomes e cargos dentro do contexto acadêmico, este estudo passou pela aprovação do CEP (Comitê de Ética e Pesquisa) da UERGS, cadastrado pelo número de protocolo 93814318.6 .0000 .8091 , aprovado sob parecer número 3.736.287. 
Em cada ambiente em que o texto foi concebido - de cafeterias simpáticas a bibliotecas acadêmicas - a lâmpada esteve minuciosamente e/ou propositalmente escondida na sanca de gesso ou escancarada fixada sobre todos. Para os menos atentos, ela está silenciosa, o que não é verdade para quem educou sua atenção para perceber os ruídos da sua presença.

A importância da luz que ela gera para que possa escrever ou um estudante de Ensino Médio Noturno Público realizar suas provas de final de semestre, ou um médico diagnosticar uma enfermidade passa despercebida. Seu papel de astro não parece combinar com a passividade - afinal, ela é passível de Logística Reversa. Seu excesso luminoso lembra a cegueira peculiar, vivida no limiar da sanidade pelos personagens de Saramago no Ensaio sobre a Cegueira. Mas pergunte, a qualquer especialista em oftalmologia, ou mesmo a um fotógrafo: o que seria da visão e dos registros da imagem sem a luz. Lâmpadas, - obrigada.

\section{Definindo conceitos}

Se "existe um fio de Ariadne que nos permitiria passar continuamente do local ao global, do humano ao não-humano (...) É O da rede de práticas e instrumentos, de documentos e traduções" (LATOUR, 2019, p.152), conforme nos elucida Latour, as redes expostas aqui, ganham mais ou menos conexões conforme o distanciamento e profundidade com que nos propusermos a observar.

Em nossa atualidade, é muito difícil traçar uma distinção entre um elemento puramente social, ou puramente tecnológico. Por esse motivo, o conceito de rede sociotécnica é tido aqui como a trama de conexões (no sentido de uma rede) que irá entrelaçar o biológico, as relações e o tecnológico de maneira conjunta. Dessa forma faço minhas as palavras de Latour quando aponta que "somos animais sociotécnicos e toda interação humana é sociotécnica. Jamais estamos limitados a vínculos sociais. Jamais nos defrontamos unicamente com objetos" (LATOUR, 2001, p. 245).

No entendimento de Moraes (2004), o conceito de rede de Latour está ligado a fluxos, alianças e movimentos. Para ela a rede de atores não é redutível a um único actante nem a uma rede; ela é composta por uma série heterogênea de elementos tanto animados quanto inanimados, conectados e agenciados.

Neste caso gaúcho, as narrativas acerca das lâmpadas, o próprio artefato de iluminação, a busca de uma Política Pública que oriente a relação com esses não humanos, leis, acordos, os riscos abstratos inerentes ao actante, humanos, poderemos seguir infinitamente as conexões permitidas pelos nós.

A multiplicidade de sentidos que a luz das inspirações de Bruno Latour traz à trama de humanos e não humanos da qual fazemos parte, ou como 
Donna Haraway elucida que nossas fronteiras entre humanidade, natureza e tecnologia não são tão distintas ou estáveis quanto imaginávamos, no mesmo sentido, toda a construção deste texto deu-se atenta ao fato de não estarmos sós. Uma Política Pública não é somente feita de humanos, é um processo social, uma conexão contínua entre elementos humanos e não humanos.

Ser humano, elemento químico, artefato, narrativas, Políticas Públicas, leis (...) aqui, possuem o mesmo peso. Haverá uma relação simétrica entre todos aqueles que se entrelaçam. Desse modo, assumo a construção do conhecimento como uma prática híbrida e heterogênea, que acontece de forma complexa e não-linear e define ao mesmo tempo o sujeito e o objeto, a natureza e a sociedade, de modo que essas "realidades" não existem separadas.

Esta rede é tecida por actantes que, a partir da perspectiva de Latour, Araújo e Cardoso (2007) são definidos como qualquer ente, elemento, artefato, humano, ou instituição que age sobre o mundo e sobre si mesmo. Dentro da perspectiva aqui assumida, elementos humanos e não humanos são possíveis formas de apresentação dos actantes, sua constituição.

No entanto, os conceitos de humano e não humano são em si mesmo problemáticos, não se esgotam em si mesmos. Para Latour, estamos em constante co-evolução e coengendramento, conectados em rede

nós mesmos somos híbridos, instalados precariamente no interior das instituições científicas, meio engenheiros, meio filósofos, um terço instruídos sem que o desejássemos; optamos por descrever as tramas onde quer que estas nos levem. Nosso meio de transporte é a noção de rede. Mais flexível que a noção de sistema, mais histórica que a de estrutura, mais empírica que a complexidade, a rede é o fio de Ariadne destas histórias confusas. (LATOUR, 2019, p. 11)

Dessa forma, admito o conceito de quase-sujeito para os humanos na perspectiva de que, pelo hibridismo das relações entre humanos e nãohumanos, acabamos por nos associar tão intrinsicamente, que fronteiras antes muito claras passam a ficar borradas. Da mesma forma os quase-objetos os são por não assumirem apenas a materialização de um artefato. De fato, as lâmpadas aqui também mobilizam humanos, constituem-se como narrativa, encapsulam riscos latentes, estabelecem laços sociais entre a SMMAM e comunidade. Sob sua luz e por si só, coparticipa nessa mobilização de comunidades e processos.

Como reiteradamente expresso, a demanda da Logística Reversa das Lâmpadas Fluorescentes surge a partir das interlocuções com a comunidade, de uma necessidade de destinação. Podemos dizer, de outro modo, que os diálogos entre o Estado e a Sociedade Civil dão origem à necessidade de 
implementação desta Política Pública. Para os autores Grisa e Scheneider (2015), uma Política Pública reflete o entendimento dos grupos sociais acerca de sua própria condição e sobre a sociedade, além dos instrumentos necessários para aperfeiçoar essa condição.

Ao observarmos a Figura 1 que representa o Ciclo de uma Política Pública, cada uma das etapas explicitadas estará descrita neste trabalho. De qualquer modo, embora tão casada com este conceito circular, propomos aqui que o que se desenrola no solo gaúcho, pelos motivos já abordados, é uma teia.

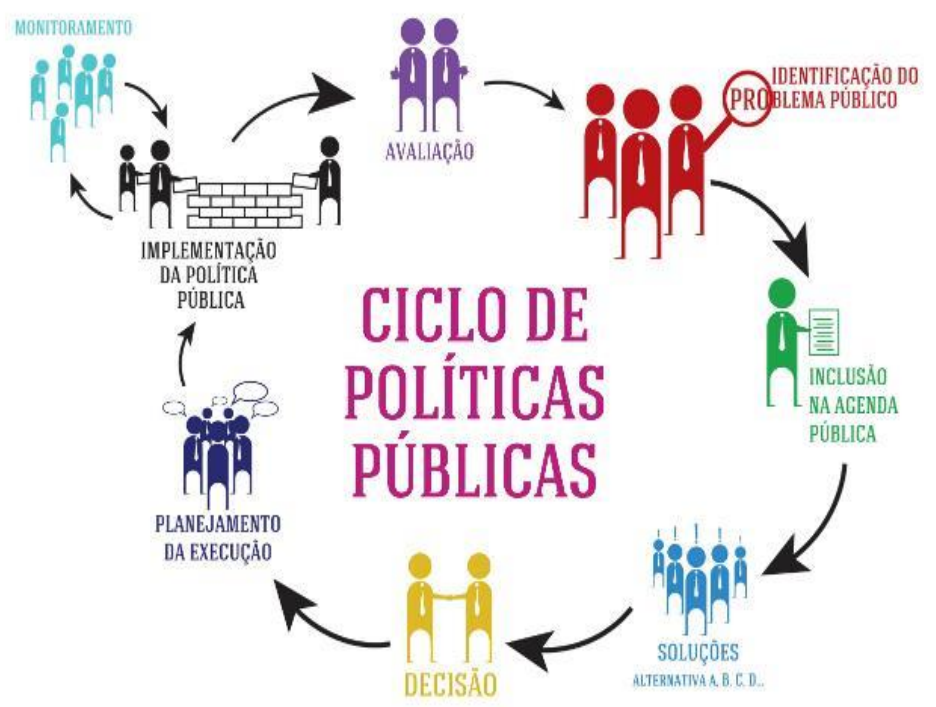

Figura 1: Ciclo de uma Política Pública Fonte: https://politicaspublicas.almg.gov.br/

Como perceberemos a partir dos desdobramentos da análise documental, das observações, conversas e entrevistas que constituem este artigo, não se iimitaram aos actantes previamente diefinicios, o processo de desvelamento trouxe consigo desdobramentos e revelou a coparticipação de diversos atuantes. Ainda tomando emprestadas as palavras de Grisa e Scheneider (2015) as ideias, instrumentos e organização de uma PP são "objeto de negociação permanente entre os protagonistas das trocas políticas, sendo suscetível de inclusões, recortes e transformações em função das relações de força e dos objetivos políticos dos diferentes atores envolvidos" (GRISA; SCHENEIDER, 2015: 22) para efetivação da PP. Como elemento mobilizador dessa rede, o antropocentrismo do risco à saúde humana, parece ser o argumento mais convincente e efetivo. Dessa forma, são protegidos os humanos dos efeitos do mercúrio, que as LF insistem em conter, quando não ameaçam liberar ${ }^{4}$. A Política Pública aparece como resultante da necessidade

${ }^{4}$ o risco da liberação é ameaça que está presente nas políticas que orientam o descarte e destinação adequados 
de amparar os humanos de ameaças latentes que agentes /actantes lâmpadas, mercúrio -apresentam. Esses actantes, que, historicamente foram relegados a um status de mero cenário, têm, aqui, reconhecido o seu protagonismo, sua atuação para a formulação de uma Política Pública.

\section{Sobre a legislação que ampara a Política Pública para Logística Reversa de Lâmpadas Fluorescentes}

A Logística Reversa de Lâmpadas Fluorescentes, no município em que este trabalho transcorre - Bento Gonçalves-RS - esbarrou inicialmente em duas dificuldades principais. A primeira: ausência do hábito, por parte do consumidor, em levar as lâmpadas ao comerciante (segundo alegação das empresas...). Este hábito vinha sendo trabalhado há mais de uma década, pois o consumidor final precisa criar uma rotina de descarte. A segunda: o custo para a destinação final ambientalmente adequada da lâmpada em desuso. A LF para ser reciclada representa ônus financeiro para o comerciante ${ }^{5}$.

Entre ao menos 34 Instrumentos Legais, Resolutivos e Normativos, Planos de Gestão e Gerenciamento, estabelecidos entre os anos de 1940 e 2019, que abordam a proteção da vida, dos ecossistemas, proteção do ambiente, controle e qualidade ambiental, gestão de resíduos sólidos, especiais e tóxicos; destaco a Política Nacional de Resíduos Sólidos (PNRS), que no ano de 2010 orienta:

Art. 33. São obrigados a estruturar e implementar sistemas de logística reversa, mediante retorno dos produtos após o uso pelo consumidor, de forma independente do serviço público de limpeza urbana e de manejo dos resíduos sólidos, os fabricantes, importadores, distribuidores e comerciantes de:(...)

V - lâmpadas fluorescentes, de vapor de sódio e mercúrio e de luz mista; (BRASIL, 2010)

Os elos responsáveis, em lei, pelo destino final das LF (distribuidores, importadores e fabricantes) não criaram, de pronto, em 2010, os mecanismos necessários para o recolhimento da lâmpada queimada. Apenas em 2017, o acordo setorial ganhou efetividade, por força do Decreto Federal 9.177 (que dispõe sobre LR). O calendário nacional previa prazo de alguns anos para a sua efetivação.

5 Ainda que o ônus previsto para reciclagem já esteja implícito no custo de venda, foi necessária a força de uma lei específica e a regulamentação de uma acordo setorial por Decreto Federal e a criação da Reciclus para o início do efetivo recolhimento da LF em desuso por parte dos fabricantes/importadores. 
Ao realizarmos uma breve pesquisa sobre os eventos de interesse envolvendo as LF e o próprio mercúrio e seus efeitos em ambientes e seres vivos, o caso emblemático em Minamata remete aos anos 1950. Desde lá, a medicina alerta que a exposição ao metal de forma contínua pode trazer consequências a saúde de organismos. No entanto, apenas em 2018, 62 anos após este evento, o Brasil assina e promulga a Convenção de Minamata sobre o mercúrio, comprometendo-se em revisar atentamente os processos e produtos com esse agente, restringindo radicalmente seu uso.

No município gaúcho em questão, desde 2008 havia uma legislação municipal ${ }^{6}$ indicando a necessidade de devolução das LF aos comerciantes. Esta lei não previa, contudo, a responsabilidade financeira para o destino ambientalmente adequado da mesma. Desse modo, o comerciante não era advertido por cobrar do consumidor final o custo, de cerca de um real por lâmpada, para a destinação da mesma. Talvez esse procedimento explicasse a "falta de hábito" da comunidade em dar a destinação adequada às LF, citada acima como problemática identificada.

Em paralelo com as iniciativas federais, começaram a acontecer mobilizações locais, como Audiências Públicas e reuniões com setores de comércio de LF e a ONG Reciclus ${ }^{7}$. Durante o período de 17 de novembro de 2017 a 02 de abril de 2019 foi possível constatar a efervescência da PP de LR no município.

\section{Lâmpadas Fluorescentes e mercúrio: participação das lâmpadas na urgência de uma Política Pública de Logística Reversa}

Para dissertar sobre a individualidade da lâmpada, assumimos inspiração no texto de Isabel Carvalho, em que aborda a perspectiva das pedras. Alinhada ao conceito de simetria ontológica que rege esta pesquisa, a reflexão do convite de Carvalho (2014, p. 69) sobre "[...] tomar o saber não como um conhecimento sobre o mundo, mas considerar regimes de conhecimento que se produzem com o mundo". Ao adotar esse conceito, assumimos todo um campo de epistemologias ecológicas que me permite pensar e imaginar a perspectiva de não-humanos que estão intrinsecamente associados ao cotidiano, partícipes ativos junto às ações humanas e nos processos de produção de significados para o mundo.

Uma lâmpada fluorescente contém mercúrio $(\mathrm{Hg})$ em sua composição, "a quantidade de $\mathrm{Hg}$ que cada dispositivo contém pode sofrer variação de acordo com o modelo, marca e também época de fabricação" (DURÃO

${ }^{6}$ A Lei 4.418 de 15 de julho de 2018 dispõe sobre o descarte de lâmpadas, pilhas, baterias, latas de tintas e de solvente, inseticida e similares no âmbito do município de Bento Gonçalves, sendo revogada integralmente pela Lei 6.423 de 17 de setembro de 2018.

7 Conforme consta no site https://reciclus.org.br/, essa é uma organização sem fins lucrativos, que foi idealizada, formada e é sustentada por Empresas Fabricantes/Importadores de lâmpadas e equipamentos para iluminação e seu público estratégico. 
JÚNIOR; WINDMÖLLER, 2008: 17). Em uma lâmpada fluorescente de 40w, os pesquisadores indicam a presença de $21 \mathrm{mg}$ de mercúrio, cuja maior parte encontra-se aderida sobre a camada fosfórica e o vidro; uma ínfima quantidade está no estado de vapor. Esses resíduos necessitam de tratamento específico, não podendo ser dispostos livremente no meio ambiente.

As tecnologias de reciclagem e destinação de LF no Brasil, conforme indicam Bacila et.al. (2014) e Mombach et.al. (2008) consistem, atualmente, na moagem simples, na trituração com tratamento químico, na trituração com tratamento térmico, no sopro e na solidificação/encapsulamento. Além dos métodos de reciclagem há disposição de LF nos aterros - ou mesmo lixões, quando este resíduo não é segregado como resíduo especial e encaminhado para a coleta seletiva de resíduos domésticos, causando um impacto ambiental negativo.

Além do $\mathrm{Hg}$ e seus compostos serem potencialmente tóxicos para os humanos, o metal representa riscos para os ecossistemas. Em seu estado puro, pode retardar a atividade microbiana dos solos e é persistente podendo transformar-se, através de ação biológica, em Metilmercúrio $(\mathrm{MeHg})$ - que é sua forma mais tóxica. Ainda, esse metal pode causar bioacumulação e biomagnificação em diferentes níveis tróficos da cadeia alimentar.

Ao tratarmos dos riscos associados à vida humana, exposição crônica por metil mercúrio está associada a danos ao sistema nervoso central. Essa exposição acontece, na maior parte das vezes, por via alimentar (SOUZA, 2013; NAZARI, 2015; BISINOTI; JARDIM, 2004). Alguns dos sintomas observados são: a perda dos movimentos voluntários, problema na articulação de palavras, perda de sensibilidade, diminuição do campo visual, dificuldade auditiva, tremores e perda de memória.

A intoxicação aguda pode trazer danos aos rins, pulmões e problemas visuais, mentais além de sintomas como salivação, fadiga, fraqueza, tremores e febre. Também tem sido constatado que vapores de mercúrio em elevadas concentrações geram lesões nos pulmões (OGA et al, 2008; MOLLERKE, 2002; LANGFORD; FERNER, 1999,). Contaminações severas podem acarretar cegueira, coma e morte. $\mathrm{O} \mathrm{MeHg}$ atravessa facilmente a barreira placentária, podendo inibir o desenvolvimento cerebral em fetos e crianças expostas ao metal.

Encontrado naturalmente no planeta, processos naturais como erupções vulcânicas, ressuspensão de partículas do solo pelos ventos, queimadas e outras intempéries contribuem para emissões naturais de $\mathrm{Hg}$. No entanto, as atividades humanas parecem ser as maiores contribuintes para o aumento dos níveis globais de mercúrio (FARIAS, 2006).

Independentemente da origem, o mercúrio estabelece um ciclo dinâmico e não totalmente esclarecido no ambiente (BISINOTI; JARDIM, 2004; FELISBERTO, 2009). Na atmosfera, sofre processos de oxirredução, migrando de um compartimento para outro. Disposto no solo pode ser transportado pela 
água até camadas mais profundas, onde poderá fixar-se ou migrar para lençóis freáticos. No ambiente aquático, além de fixar-se nos sedimentos, pode sofrer a ação de bactérias e passar para sua forma orgânica, metilada, atingindo a cadeia alimentar na forma de metilmercúrio. Em qualquer um desses momentos ele pode voltar à forma de vapor e retornar à atmosfera.

\section{Conversas sob a luz: seguindo as conexões de uma rede sociotécnica permeada de tensões}

O uso de lâmpadas fluorescentes demonstrou-se habitual tanto nos prédios privados quanto nos da esfera pública e serviços urbanos. Datam do ano de 2013 as primeiras correspondências internas, entre setores da municipalidade, para efetivação de uma LR nos moldes previstos pela PNRS. O setor de compras (licitações, empenhos e tomadas de preços) foi mobilizado, através de correspondências oficiais ${ }^{8}$, para que constasse, documentado, a necessidade do(s) fornecedor(es) de lâmpadas realizarem a coleta do material inservível. O passivo ambiental de lâmpadas utilizadas nos prédios e serviços públicos começava a avolumar-se. O registro feito em 2012, pela equipe que executou o Plano Municipal de Gerenciamento Integrado de Resíduos Sólidos, evidencia a aglomeração destes artefatos.

As lâmpadas avolumavam-se em um container contíguo à área de estacionamento enquanto aguardavam destinação, até meados de 2013, quando foram acomodadas em uma garagem locada, também nas proximidades da Secretaria de Meio Ambiente, que na época atendia ao lado da linha férrea. Em 2014, as lâmpadas armazenadas avolumavam-se em uma estimativa de 1000 unidades, informação expressa pelo Plano Municipal de Gerenciamento Integrado de Resíduos Sólidos de 2014. "Se temos centenas de mitos contando como o sujeito construiu o objeto não temos, contudo, nada para nos contar o outro lado da história: a maneira pela qual o objeto faz o sujeito" (LATOUR, 2019:103). Ela, a lâmpada, se torna fundamental para as atividades humanas corriqueiras ao mesmo tempo que beira a obsolescência. A presença das lâmpadas deu visibilidade à necessidade de implementação de uma Política Pública em vigor há quase uma década.

Naquele momento, apresentavam-se como actantes nesta rede, além das lâmpadas armazenadas, os servidores públicos da SMMAM - ao insistirem em solicitar aos servidores públicos do setor de compras a sua destinação ambientalmente adequada, pois ficaria a cargo destes servidores gerenciar este produto quando o mesmo recebesse o status de resíduo. Todo passivo ambiental ficaria a cargo da SMMAM. Em se tratando de resíduo, a SMMAM torna-se responsável dentro do sistema adotado pelas pastas da municipalidade. Esse gerenciamento passava, naquele momento, pelo

${ }^{8}$ Entre os anos de 2013 a 2018 constam, ao menos, cinco correspondências oficiais atentando ao fato da necessidade de expressar, formalmente, a necessidade da empresa fornecedora de recolher, sem ônus, a lâmpada queimada.

Revbea, São Paulo, V. 16, № 4: 451-474, 2021. 
obstáculo do não recolhimento gratuito por parte dos fornecedores e pela impossibilidade administrativa de usar recursos do órgão para o descarte ambientalmente adequado. Esses dois elementos presentes - dinâmica dos fornecedores e da administração pública - imobilizavam o setor para dar conta da demanda que ora se apresentava

Não somente as LF provindas das entidades e órgãos públicos geram um passivo. Os mais de cem mil habitantes também geram essa modalidade de resíduo. A Lâmpada vai assumir diferentes status durante essas negociações. Assumo que "a partir do momento em que seguimos os rastros de qualquer quase-objeto, ele nos aparece algumas vezes como coisa, outras como narrativa, outras ainda como laço social, sem nunca se reduzir a um simples ente" (LATOUR, 2019:111). Acima já apareciam como um resíduo, ou passivo, um bem de consumo transformando-se em risco potencial, passando a tema de legislação, a assunto de acordo, a actante de estudos, também um ente latente de um parlamento, um agregado, como convido o interlocutor a compartilhar no final deste capítulo.

Em maio de 2017, através de ofício o Secretário de Meio Ambiente, reitera ao setor responsável atentar para a logística Reversa das LF e outros itens inclusos no artigo 33 da PNRS. Ainda em 2017, a correspondência oficial datada de junho, responde ao ofício do Promotor de Justiça local, informando sobre o passivo ambiental de lâmpadas no município, armazenadas na SMMAM e na SEGIMU - Secretaria Municipal de Gestão Integrada e Mobilidade Urbana.

Nessa correspondência informa a existência de milhares de lâmpadas sob a tutela do município, no endereço da Avenida Osvaldo Aranha, em aguardo de um posicionamento sobre o acordo setorial. Esse acordo firmado em 2014 prevê, em seu Anexo I, que Bento Gonçalves seria contemplado no quarto ano de vigência do esquema de logística com pontos de recebimento; no entanto, seu vigor efetivo inicia em 2017, com previsão de atendimento para 2020.

No mesmo ano, o Procurador da República inquere sobre o andamento da Logística Reversa, através de ofício 814/2017 (inquérito civil 1.29.012.000155/2016-17), com considerações sobre 0 meio ambiente constantes na Constituição Federal e também na PNRS, tecendo, em 3 laudas, a recomendação da Entidade sobre o assunto. Em resposta ao Órgão Federal, o Secretário de Meio Ambiente informa que, em novembro daquele ano, seria realizada uma Audiência Pública, a fim de promover trabalho preventivo de esclarecimento aos comerciantes sobre a sistemática de Logística Reversa 


\section{A Audiência Pública como aposta: conflitos para efetivação da Política Pública}

A partir deste anúncio de Audiência Pública há o início do corte temporal desta pesquisa. Em razão da atividade profissional exercida por uma das autoras deste artigo, esta inicia o processo de pesquisa inserida no campo de antemão, construindo o caminho da pesquisa, enquanto o meio também a transformava. Assim, de certo modo, tornou-se impossível dissociar o papel de pesquisadora do papel de servidora pública.

$\mathrm{Na}$ data de sete de novembro de 2017, em conversa informal com outros colegas da Secretaria de Meio Ambiente, relacionados diretamente com a Logística Reversa de LF, foram abordadas suas expectativas acerca da Audiência Pública que seria realizada em 17 de novembro daquele ano, e o papel que estimavam que este evento poderia representar na questão da LR das lâmpadas.

\section{Gestor de Meio Ambiente}

Conversamos na sala do Secretário, na ocasião localizada na Avenida Marechal Floriano, 85, no quarto andar - bem longe do passivo ambiental das lâmpadas, registrado em forma de imagem. Talvez passe despercebido o fato de que apenas os setores administrativos (não os de depósito e operacionais) haviam migrado para o novo endereço no centro da cidade.

Nos pouco mais de quatro minutos de conversa, o Secretário (que estava em seu primeiro ano à frente da pasta), como boa parte dos gestores, com fala bastante articulada, teceu comentários esperançosos acerca da Educação Ambiental ${ }^{9}$, especialmente a partir do panfleto elaborado pelo Consórcio Intermunicipal de Desenvolvimento Sustentável da Serra Gaúcha (CISGA), apresentando o papel importante do consórcio na gestão compartilhada dos resíduos da Serra Gaúcha. Quanto às perspectivas da Audiência Pública, a via como um passo à frente nas questões de Logística Reversa.

\section{Enfim, o evento tão aguardado}

Chegada a grande data da Audiência Pública, na Câmara de Vereadores, de sede ampla e antiga, mas conservada, as impressões estenderam-se um pouco além do espaço físico. Uma mescla de interesses parecia pairar entre os presentes. Representantes da SMMAM pareciam transpirar um empoderamento altivo. Sob os comerciantes, expressões de descontentamento e talvez desconfiança. Sob os representantes do Ministério

${ }^{9}$ Creio ser interessante mencionar que não há como mensurar, mas essa declaração pode ter sofrido algum atravessamento em razão do papel desempenhado pela pesquisadora junto ao Setor de Educação Ambiental da Secretaria Municipal do Meio Ambiente.

Revbea, São Paulo, V. 16, № 4: 451-474, 2021. 
Público, emanava o poder (em algum descuido, talvez houvesse reverência velada). Sob a imprensa a avidez pelo novo, poderia ser descrita - como o aroma quente de um pão saindo do forno - a ser entregue aos consumidores de informação local.

Como havia sido previamente agendado, a Promotora de Justiça convidada a falar sobre o tema da LR de LF concedeu-me um tempo para conversarmos sobre o evento.

\section{Promotora de Justiça e Coordenadora do Centro de Apoio e Defesa do Consumidor - Ministério Público - RS}

Muito gentilmente a Promotora explicitou sobre o seu trabalho na esfera estadual, com o Programa Res-Sanear. Explanou que todos os municípios do estado estavam buscando meios para a logística de modos diversos (via Planos Municipais, Termos de Cooperação e Acordo Setorial). Portanto, podese inferir que esta demanda não era exclusiva dos bentogonçalvenses. A orfandade das lâmpadas em desuso não era apenas uma demanda local. Em novembro de 2017, segundo a Procuradora, apenas um grande varejista multinacional estava aderido à Logística Reversa das lâmpadas, no Estado do Rio Grande do Sul - na cidade de Porto Alegre. Segundo a Procuradora, havia um atraso na destinação adequada das lâmpadas, mas o MP atuava de forma fiscalizadora, não agente, e busca, em diferentes locais, para o consumar-se das leis. Afirmou que uma legislação municipal era peculiar em solo gaúcho.

Começou a abrolhar, portanto, em novembro de 2017, no estado gaúcho, uma destinação ambientalmente adequada das LF. Por meio de acordos setoriais que se originam de pressões aos municípios através de processos administrativos motivados pelo Ministério Público, que acabavam por mover a municipalidade e os comerciantes locais. À época, a Reciclus inaugurava um ponto de coleta no estado, conforme previsão em acordo ${ }^{10}$.

Em solo bentogonçalvense, entre os 45 presentes, estavam representantes de uma das casas de material elétrico mais tradicionais da Cidade. Muito interessados nas determinações que viriam a partir deste momento. Convidei para que conversássemos sobre as LF.

\section{Representantes (lojistas) do setor de varejo das Lâmpadas Fluorescentes}

Colocaram em pauta que estava partindo do consumidor final a troca da escolha da lâmpada fluorescente pela lâmpada de LED, especialmente pela redução no consumo de energia elétrica. Mesmo assim, relataram que cerca de duas mil LF (apenas neste estabelecimento comercial) eram recebidas

10 O cronograma com a estimativa de Pontos de Entrega e recipientes de coleta por fase e por Município é o Anexo I do Acordo Setorial, conforme consta no site do Sistema Nacional de Informações sobre a Gestão dos Resíduos Sólidos (SINIR), www.sinir.gov.br.

revista brasileira educação ambiental 
mensalmente. $O$ custo para a reciclagem destas era bancado pelo consumidor que as entregava no balcão - muitas vezes ao adquirir uma lâmpada nova. Ressaltaram que, algumas marcas específicas, diante de uma burocracia de meter inveja aos balcões públicos tupiniquins, aceitavam suas lâmpadas inutilizadas, sem custo - mas acompanhadas de nota fiscal de venda que o consumidor deveria ter zelado durante toda a vida útil e entregue juntamente com a lâmpada queimada. $O$ anseio e expectativa expressos pelos comerciantes era que os fornecedores recebessem a LF em desuso, pois no caso da obrigatoriedade de recebimento, sem o aporte da reciclagem por parte dos importadores/fabricantes, o custo dessa descontaminação seria incluído mais uma vez - no preço final da lâmpada. Era de interesse, pelo percebido, que a LR acontecesse de forma a não os onerar, ou que fosse vinculada ao pagamento por parte do consumidor.

Nada ficou acordado no evento. Representantes do legislativo solicitaram vistas. A Regulamentação da lei 4.418 não aconteceu. $O$ destino das LF, na saída da audiência era o mesmo que na entrada: incerto. Entretanto, agora com muito conhecimento compartilhado/deferido, opiniões e aspirações sobre o assunto discursado na casa do Legislativo Municipal.

\section{O tempo seguinte}

Seguindo a linha temporal, cerca de vinte dias após a Audiência já referida, o Procurador de Justiça local cedeu-me um tempo para conversarmos sobre a Logística Reversa. Recebeu-me em uma sala impessoal, reservada para visitas e reuniões, na sede do Ministério Público Federal (MPF), Procuradoria da República.

\section{Procurador de Justiça}

O fazer cumprir das leis que orbitam os órgão e esferas federais está sob a responsabilidade do MPF. O procurador explanou quanto ao inquérito civil instaurado, buscando averiguar a situação do município quanto à Gestão de seus RSU, ficando este sob o risco de receber apontamento. Neste caso, haveria uma indicação para que não mais recebesse recursos federais, caso não atuasse de maneira a estar cumprindo a lei e, de maneira atrelada, promovendo os meios para a LR.

Após um pigarro - e um "veja bem" - iniciou: "sempre que há custo econômico envolvido", ponderou, indicando que o investimento em logística por parte do comerciante podia estar sendo colocado na ponta do lápis e não ocorrer - visto que aparentemente não traz retorno direto para o mesmo. Colocou como imperativo para a efetivação da política em jogo, um engajamento coletivo, pois concluiu que a falta de hábito do consumidor poderia estar se apresentando como entrave para efetivação da LR. Não acreditava que a lei, por si só, seria suficiente para mudar comportamentos. A 
lógica econômica de tirar o máximo proveito pelo mínimo de dispêndio financeiro, na opinião do Procurador, é algo que motiva decisões. Atrelava tanto a conduta e o comportamento correto por parte do consumidor, caso houvesse, quanto por parte do empreendedor, sugerindo uma espécie de "multa" para quem não destinasse corretamente seus resíduos. Indicou esse como um dos caminhos para que aconteça, de forma eficaz, a LR no pósconsumo.

No momento que, a partir da narrativa da promotoria, a responsabilidade pela efetivação da Política Pública - através da correta destinação da LF desloca-se para o consumidor, ela dissipa-se. Não há um rosto a ser identificado, um autor com CNPJ para ser notificado, uma administração Pública para ser apontada. É interessante destacar que em nenhuma outra narrativa o consumidor é indicado como o elo responsável pela não efetivação da Política Pública na realidade local. Ao contrário, a realidade local revela o consumidor como um partícipe ativo da Logística Reversa: ele armazena, segrega, busca soluções para o seu então resíduo. Podemos supor a partir dos indícios de proximidade entre o Setor de Educação Ambiental e a comunidade que, o hábito do consumidor final em realizar a segregação na fonte deste resíduo pode ser resultado das intensas ações em Educação Ambiental no município ${ }^{11}$. Na Figura 2 (próxima página) representamos o que as entrelinhas puderam ter suprimido. Até 17 de setembro de 2018, a inalterabilidade do quadro da LR no município permaneceu. Nessa data, a Lei 6.423 revoga integralmente a Lei 4.418. Em sua ementa dispõe sobre o descarte, 0 recolhimento e a destinação adequada - entre outros passíveis de LR - das LF.

Com redação muito semelhante a PNRS estabelecia, em resumo, que com exceção dos consumidores, todos os participantes dos sistemas de logística reversa deveriam manter atualizadas e disponíveis as informações completas sobre a realização das ações da LR. Ficariam responsáveis importadores, fabricantes, distribuidores e comerciantes dos produtos por manter nos estabelecimentos recipientes para a coleta adequada, acondicionamento e armazenagem temporários das LF. Imputaria, assim, aos consumidores, apenas descartá-las em local apropriado, sem ônus.

11 O município poderia ser responsabilizado por não fazer cumprir a Lei de LR das LF, que depende de aportes financeiros das empresas que Fabricam/Importam/Comercializam as LF para que a sua destinação seja feita corretamente. O município não tem como pressionar os Fabricantes/Importadores, que destinam recursos para a Reciclus realizar a LR. Do mesmo modo, sob o risco de apontamento, não poderia usar recursos próprios para fins de LR das lâmpadas que usa ou a dos munícipes. O município cria mecanismos para agir sobre as entidades privadas que comercializam LF no seu território (mas não de quem realiza as compras por licitação). O consumidor final, por sua vez, parece ser penalizado, pois os custos da LR recaem para ele tanto no preço embutido da lâmpada, quanto na opção de destinação final adequada nos comércios da cidade. 


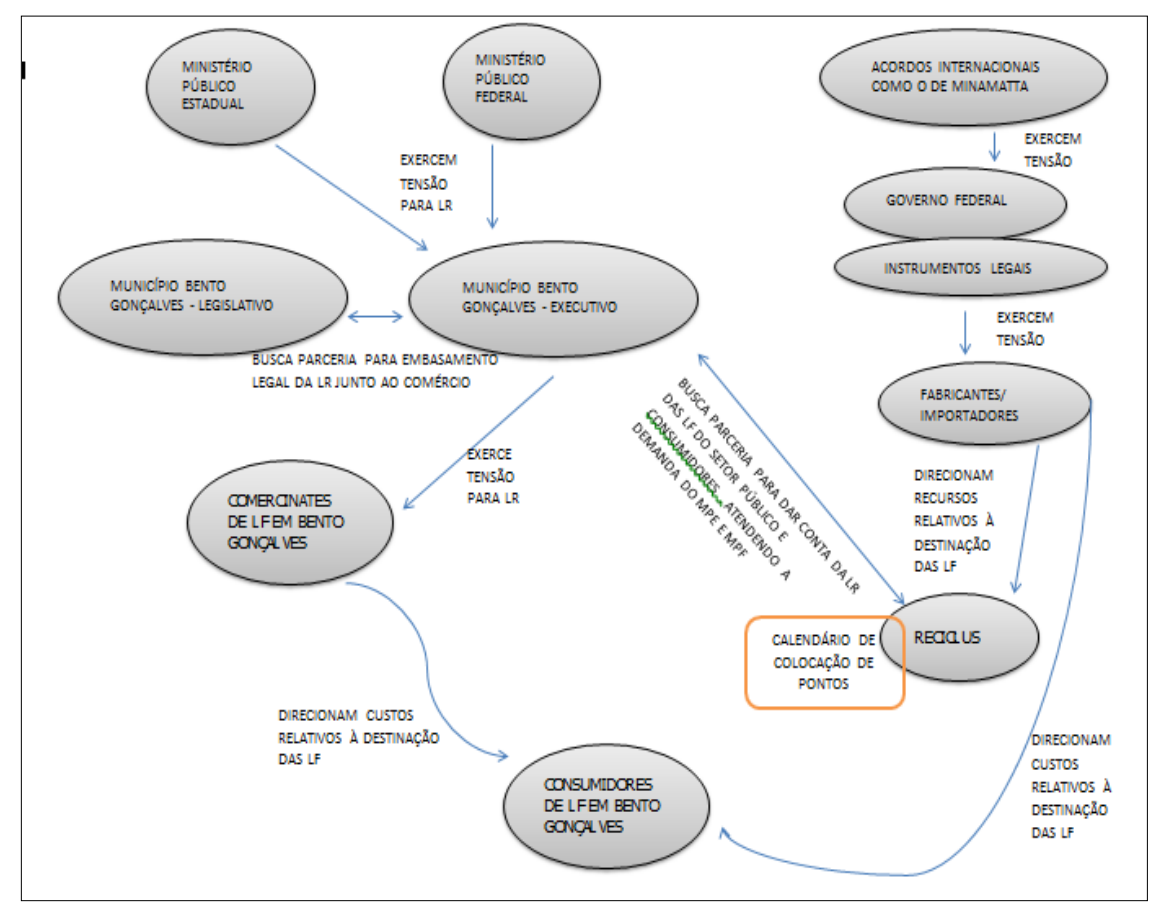

Figura 2: Implicações, forças e tensões na rede envolvendo a Logística Reversa das Lâmpadas Fluorescentes.

Fonte: Autoras (2020).

O descumprimento ao disposto sujeitaria ao infrator, em sequência: advertência; multa de duas URMs (Unidades de Referência Municipal), se consumidor; e de 34 trinta e quatro URMs, se comerciante ou distribuidor; 67 URMs, se importador ou fabricante; e, finalmente, cassação do alvará. Nos casos de reincidência, o valor da multa seria cobrado em dobro.

O tempo que se seguiu até o encontro seguinte, em 5 de outubro de 2018, foi marcado pela expectativa da mudança da nova promulgação.

\section{Fiscal do Meio Ambiente, Presidente do Conselho Municipal do Meio Ambiente (COMDEMA) e representante do município no CISGA}

Houve uma conversa sobre a temática da LR das LF. Naquela oportunidade, os rumos da conversa voltaram-se, preponderantemente, para a atuação como representante do CISGA. Relatou que não só Bento Gonçalves, mas todos os municípios dos arredores estavam ligados ao vivenciarem a problemática da Logística Reversa da LF. Relatou a recorrência do problema no Brasil inteiro, avaliando a lei como um passo importante na sustentabilidade. Relatou que, contatada, a Reciclus recusou diálogos e negociações para recebimento de lâmpadas alegando a data para contemplação do município ainda não ter sido atingida. Relatou que não houvera nenhuma denúncia quanto ao não cumprimento da Lei recém-aprovada por parte dos comerciantes. Desta forma, relatou o Fiscal: ainda "não fez-se valer a lei" em Bento Gonçalves. 
$\mathrm{Na}$ região, o Acordo Setorial começava a figurar em cidades de maior porte - como em grande rede de mercados em um Shopping Center de um município vizinho - dispositivos da Reciclus, criados com o propósito da LR das LF. Eram enormes dispositivos que ficavam à vista, para recebimento adequado das lâmpadas.

Sem muita repercussão na mídia local ou alarde por parte dos comerciantes, a lei parecia "não ter pego", no linguajar popular. Embora a orientação continuasse a ser de entregar nos locais que as comercializam, não houve mobilizações por parte dos comerciantes, ou mesmo dos consumidores. No Setor Público, os diálogos entre as secretarias, no assunto de lâmpadas, pareciam seguir a sequência de orientações verbais acompanhadas de correspondência oficial, como quando em novembro de 2018, o Secretário de Meio Ambiente informou ao Secretário da SMGIMU sobre a necessidade de não armazenar as LF e similares em espaços da municipalidade, citando os argumentos legais para tanto.

Então, em 21/11/2018, através do empenho municipal, foram destinados recursos do Fundo Municipal do Meio Ambiente para o recolhimento, transporte, tratamento e disposição final das lâmpadas sob a tutela da municipalidade.

Se, por um lado, através desta medida estratégica, as lâmpadas deixavam de ser um problema para o órgão público, na medida que não mais haveria apontamentos do Ministério Público Estadual ou Federal pelos passivos que avolumavam-se em setores comuns; por outro, fora jogada luz e foco à necessidade de solução para as LF dos consumidores domésticos.

Esse foco se deu por correspondência oficial, emitida por ordem do Procurador Público. O teor da correspondência de 14 de janeiro de 2019, solicitava, em quatro linhas, o andamento do atendimento da Recomendação do Ministério Público, de 2017, em um prazo de 20 dias. Em resposta, o ofício da SMMAM de 30 de janeiro de 2019, informou ao procurador que: o setor de Educação Ambiental estava atuando junto à população (nas estratégias: palestras, visitas, encontros e outras sensibilizações); sobre os procedimentos de Logística Reversa; que o site da Prefeitura estava sendo utilizado para informar a população sobre a LR; que o Licenciamento Ambiental estava estabelecendo condições e restrições para o cumprimento da mesma (como mencionou a Bióloga, em 2017); que o comércio local foi convidado a reuniões (prévias à Audiência Pública) para tomarem ciência da Lei da LR; finalmente, que o Setor de Educação Ambiental, na Pessoa de sua Coordenadora, estava verificando com a Reciclus a possibilidade da antecipação dos ponto de coleta das lâmpadas - previstos apenas para 2020.

Esse contato com a Reciclus, apesar de realizado anteriormente por demais servidores ou pelos membros do CISGA, neste momento mostrou-se exitoso - uma luz no fim do túnel. Após inúmeras transferências de telefonemas, os membros da organização pareceram interessados em antecipar o calendário, instalando os pontos de recebimento um ano antes do

revista brasileira educação ambiental 
previsto pelo calendário do Anexo I do Acordo Setorial. Para tanto, solicitavam o auxílio do Poder Público local para intermeio de diálogo com os comerciantes, definição dos pontos de coleta e ações de divulgação Educação Ambiental - junto à comunidade.

Se as habilidades pessoais de comunicação de um agente puderam ser, em um primeiro momento, percebidas como principais influentes para a aproximação de um diálogo entre a ONG e a municipalidade, o não alcance das metas de recolhimento em outras localidades pode ter sido muito influente na antecipação do calendário para a cidade.

A negociação e alianças com grupos internos - SMAMM, SMOB, Secretaria de Finanças - e externos - ONG, MPF, comerciantes, consumidores - sela uma parte da trama desta rede sociotécnica, que traria a solução local para a implementação da Logística Reversa das Lâmpadas Fluorescentes.

No mês seguinte ao contato, iniciou-se uma mobilização com diferentes setores da SMMAM local, para o chamamento dos comerciantes de Lâmpadas Fluorescentes, com o objetivo de prepará-los para uma reunião, em dois de abril de 2019, em que um membro responsável da Reciclus viria até o município, apresentaria os termos de um acordo de comodato do recipiente coletor e esclareceria termos referentes à disponibilização do equipamento e sobre a coleta das lâmpadas.

$\mathrm{Na}$ data de primeiro de abril, na denominada sala de cinema da Casa das Artes, o público presente era constituído, essencialmente, por comerciantes e representantes das entidades dessa classe, representantes do Poder Público, em especial da SMMAM, representantes do COMDEMA e escolares do Ensino Médio - convidados para assumirem o papel de multiplicadores da informação entre os estudantes.

O Representante da Reciclus explanou as ações de LR que agradaram os comerciantes com pontos de recebimento. Os comércios não contemplados com pontos de recebimento saíram de lá também satisfeitos: poderiam receber as LF e estabelecer parcerias com pontos de recebimento cadastrados, levando as lâmpadas para estes locais em datas agendadas para serem acondicionadas nos caminhões de recolhimento nos dias de coleta. Também acordado em contrato, como obrigatoriedade do comerciante, a necessidade de aviso quando o recipiente estivesse a $80 \%$ de sua carga máxima, para agendamento de recolhimento antes de atingir a capacidade máxima do coletor e amontoamento desnecessário, que propiciasse quebra. Sem receber os contratos assinados no local, mas com aceites sem protestos, cada estabelecimento necessitou entregar, posteriormente, o contrato, por meio digital, à Associação. No mesmo dia, o representante da ONG recebeu-me no Hall do Hotel em que estava hospedado para uma conversa. 


\section{Representante da ONG Reciclus}

$\mathrm{Na}$ oportunidade, foi pedido que falasse um pouco mais sobre a atuação da Associação, sobre as motivações, sobre a adesão dos pontos de recebimento, as resistências e conquistas na atuação, bem como sobre a inclusão antecipada do município no calendário de recebimento.

Revelou que a Região Sul, com menos pontos de recebimento, relativamente, vinha recolhendo mais LF do que qualquer outra região do país, atribuindo tal fato a uma "doutrina sustentável", com engajamento da população diferenciado em relação a outras regiões brasileiras. Ressaltou, na ocasião, a evidência de que há discrepância entre a Região Sudeste, com 680 pontos, recolhendo 280 toneladas de LF e a Região Sul, contando com 270 pontos e recolhendo 380 toneladas, um comércio menos engajado com pulação mais ativa - avaliou.

Desvelou, ainda, que em 2 anos de programa foram recuperados $30 \mathrm{~kg}$ de mercúrio, comercializados a mil e duzentos reais - o que não garantia a autossuficiência desta LR, que tem a estimativa de recolhimento de 4 milhões de lâmpadas. Em suas palavras "Consciência para a gente mudar: pequenas coisas para começar a fazer o certo" avalia, em relação ao papel da LR das lâmpadas e à recuperação da quantidade ínfima de mercúrio.

Embora inquirido a respeito do recurso financeiro para subsidiar essa recuperação, essa informação não foi revelada e, evasivamente argumentado como uma equação complexa. Emergiu da conversa também o objetivo do Programa de recolher $20 \%$ das lâmpadas colocadas no mercado, o que nas contas da Associação seria o equivalente a 24 milhões de lâmpadas/ano com $100 \%$ do programa implementado até 2021.

O Representante apontou que a peculiaridade local da participação do Poder Público no levantamento dos Pontos de Coleta; a sensibilização dos comerciantes e população para participação; o interesse e contato com o Programa; a expectativa de um montante significativo de recebimento e o fato de não terem alcançado as expectativas de recolhimento em outras regiões foram os fatores propulsores para Bento Gonçalves conquistar uma destinação ambientalmente adequada das LF, no ano de 2019, por meio do Acordo Setorial (2014) de Logística Reversa instituído pela PNRS (2010).

Nos meses que seguiram o firmamento de contrato entre os comércios e a Reciclus, as lâmpadas figuraram nos dispositivos destinados ao recebimento. Tanto na área pública como em condomínios privados, parece ser um hábito cultural da população local segregar diferentemente dos resíduos usuais as LF. Contudo, levar voluntariamente o resíduo a pontos de recebimento pode ser um ponto de melhora nas atividades de Educação Ambiental para a obtenção da excelência. Como efeito, no período de abril a dezembro de 2019 foram captadas, em Bento Gonçalves, 58.566 unidades $^{12}$ de Lâmpadas

12 Informação fornecida por e-mail pela ONG Reciclus, a pedido das autoras.

revista brasileira educação ambiental 
Fluorescentes nas 80 coletas realizadas nos 16 Pontos de Recebimento da cidade.

A EA parece ter tido um papel fundamental para que ações sustentáveis passassem do discurso para a ação cotidiana da população, influenciando suas escolhas mesmo no descarte de inservíveis. A atuação do Ministério Público Estadual e Federal demonstrou ter tido um grande peso na busca de soluções para LR, talvez pela possibilidade de restrição de recursos.

A Reciclus aparece com actante resolutivo para efetivação da política de LR. No entanto, pode haver questionamento do porquê de sua atuação quase uma década depois do previsto na PNRS, ao passo que começou a realizar a LR em um momento em que a obsolescência das LF está percebida em diferentes setores da sociedade, como entre os agentes públicos, comerciantes de materiais elétricos e até mesmo pelos membros da Reciclus.

Proponho na Figura 3 um emaranhado que tece essa rede sociotécnica descrita localmente, com a evidência de alguns pontos de tensão; sua incompletude é aqui, desde já assumida, por se tratar de uma das perspectivas possíveis sobre o assunto. O Paradoxo dos pontos sempre locais em um emaranhado global descrito por Latour (2019) mantêm-se. Trata-se de uma espécie de mapa, circunscrito em um contexto temporal e espacial específico.

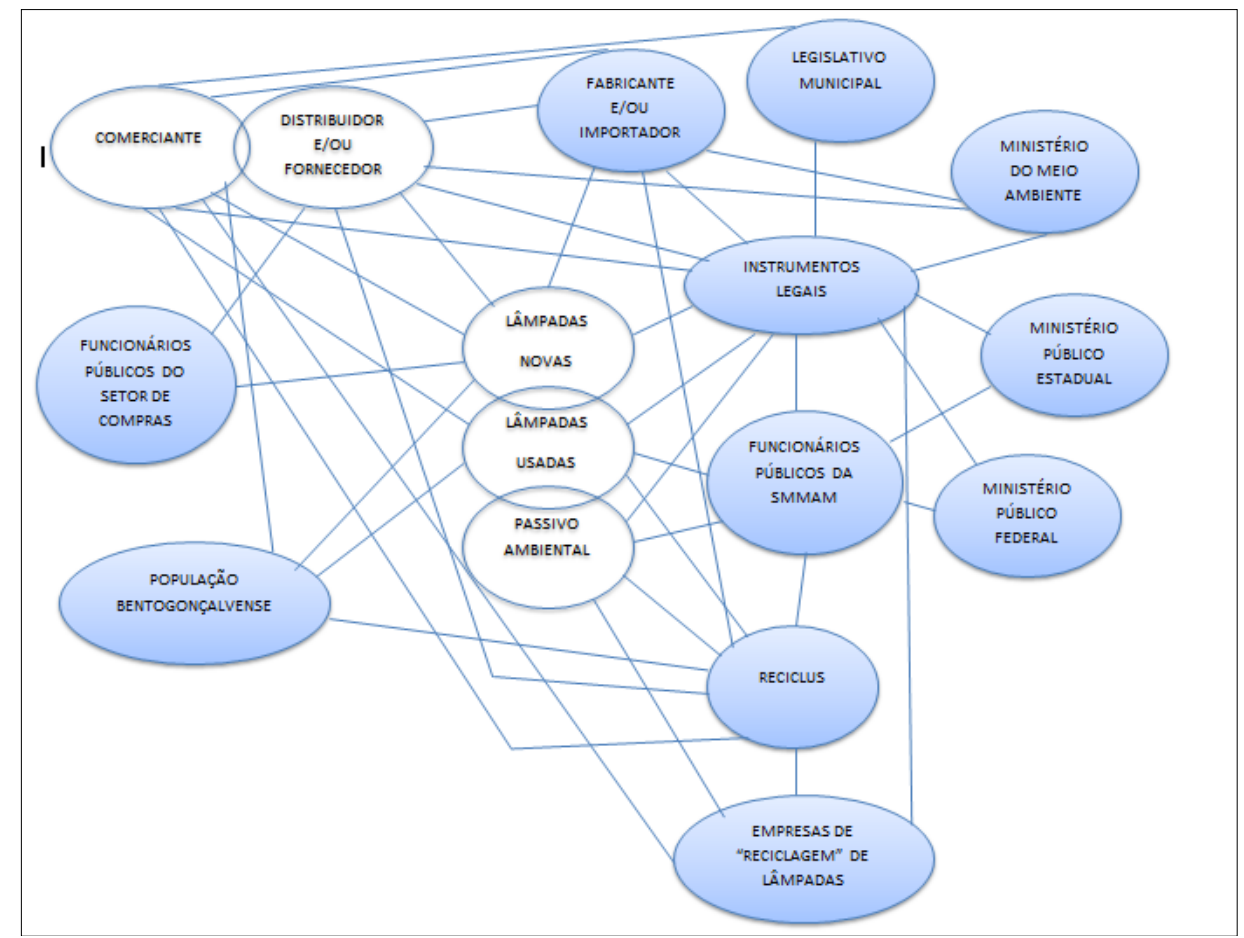

Figura 3: Representação da Rede Sociotécnica das Lâmpadas Fluorescentes.

Fonte: Autoras (2020) 


\section{Reflexões Conclusivas}

Apresentamos, neste artigo, um olhar possível para as tramas e tensões que envolveram a implementação da Política de Logística Reversa através desta abordagem pesquisador-participante inserida na Secretaria de Meio Ambiente do Município de Bento Gonçalves. Convidamos a perceber que, para a efetivação desta Política Pública, foi necessário muito mais que a previsão em Lei. A implementação de uma Política, assim, é sempre muito mais complexa do que promulgar ou sancionar uma lei. A implementação efetiva de uma Política implica uma tessitura, conexões constantes e mutantes entre actantes humanos e não humanos.

Diante da presença contundente de actantes como mercúrio, lâmpadas sem destino, Ministério Público, leis, ofícios, denúncias participaram com força para a tensão da rede, torna-se evidente o que esta análise se propôs a trazer à luz: não humanos, parecem ser sempre passíveis de ordenamento, apresentam-se por vezes como objetos inanimados. Contudo, se olharmos com atenção, podem ganhar posições simétricas na rede, assumindo status de possibilitar, restringir e acompanhar ações, demandar cuidados que incitam a produção de Políticas Públicas.

O objetivo geral deste artigo, dar visibilidade e trazer à tona as vozes e os silêncios dos actantes envolvidos na efetivação dessa PP estão expressos e especialmente representadas pelas Figuras que representam as redes sociotécnicas.

A eficácia da Política Pública de Logística Reversa deu-se através de uma soma de fatores, que passaram pelo passivo ambiental de LF, pela Legislação Local, pela atuação do Ministério Público, pela presença do Licenciamento e Fiscalização Ambiental, existência de Conselho de Meio Ambiente, engajamento dos Consumidores e Comércio, articulação de Servidores Públicos, pela Educação Ambiental, enfim, uma verdadeira rede que procurou-se evidenciar, dentro das limitações deste estudo. Ao pensar na Logística Reversa, em um primeiro momento, essas implicações não são tão presentes, parecem invisibilizadas por nossa tendência de separação entre aquilo que é da ordem do social e o que pertence ao mundo natural.

$O$ que pode ter influenciado uma morosidade tamanha para a implementação da LR? Mesmo a Logística Reversa das Lâmpadas Fluorescentes não sendo a primeira Logística Reversa a ser implementada em Bento Gonçalves, esses actantes foram os que demandaram maior atenção. Uma hipótese pode ser associada ao fato de ter tantos riscos associados às LF e também ao fato que a elas não é assegurada um valor mercadológico após a obsolescência, o que acarreta um investimento por parte do produtor/importador para, de fato, encaminhar o produto inservível para um destino ambientalmente adequado.

Parece ser do Estado a responsabilidade de criar uma Constituição e mecanismos que pudessem assegurar um meio ambiente em equilíbrio para os 
habitantes da esfera compartilhada por humanos e não humanos; mas há indícios, no caso apresentado, de que a efetivação de uma Política Pública é, sobretudo, um campo de negociações. Não tenho hipóteses que possam separar deste tema a força econômica das organizações frente à legislação elaborada pelo Estado.

O assunto não se esgota neste artigo. A trama que envolve a Política Pública de Logística Reversa das Lâmpadas Fluorescentes se mostrou cheia de nós e de negociações; talvez menos atrelada a questões ambientais e conhecimento técnico- científico e mais com os relacionamentos entre questões econômicas, tensões políticas e seus afetos.

\section{Referências}

ARAÚJO, R. F. de; CARDOSO, A. M. P. A ciência da informação como rede de atores: reflexões a partir de Bruno Latour. Disponível em: $<$ http://200.20.0.78/repositorios/handle/123456789/139>Acesso em : 25 de maio de 2020.

BACILA, D. M.; FISCHER, K. ; KOLICHESKI, M. B. Estudo sobre reciclagem de lâmpadas fluorescentes. Eng. Sanit. Ambient. [online]. 2014, vol.19, n.spe, pp.21-30.

BENTO GONÇALVES. Plano de gerenciamento integrado de resíduos sólidos. Elaborado a pedido CISGA Por Global Engenharia Ambiental Ltda, Janeiro De 2018. Bento Gonçalves, RS, 2018. Disponível em: $<$ http://www.bentogoncalves.rs.gov.br/downloads/Smmam/Plano-de-

Gerenciamento-Integrado-de-Residuos-Solidos-Cisga-2018.pdf> Acesso em: 24 out. 2019.

BENTO GONÇALVES. Lei $\mathbf{n}^{\circ} \mathbf{4 . 4 1 8}$, de 15 de julho de 2008, dispõe sobre o descarte de lâmpadas, pilhas, baterias, latas de tintas e de solvente, inseticida e similares no âmbito do município de Bento Gonçalves. Disponível em: $<$ http://www.bentogoncalves.rs.gov.br/legislacao.html> Acesso em: 12 de maio de 2020.

BISINOTI, M. C.; JARDIM W. F. O comportamento do metilmercúrio no ambiente. Quím. Nova, vol.27 no.4 São Paulo July/Aug. 2004.

BRASIL. Acordo Setorial de Lâmpadas Fluorescentes de Vapor de Sódio e Mercúrio e de Luz Mista e seus Anexos (2014). Disponível em: $<$ https://sinir.gov.br/images/sinir/Acordos Setoriais/02\%20-

$\% 20$ Acordo\%20Setorial\%20de\%20L\%C3\%A2mpadas.pdf> Acesso em: 20 de dezembro de 2019. Acesso em: 23 nov. 2018.

CARVALHO, I. C. M. A perspectiva das pedras: considerações sobre os novos materialismos e as epistemologias ecológicas. Pesquisa em Educação Ambiental, vol. 9, n. 1 - págs. 69-79, 2014. 
DURÃO JÚNIOR, W. A.; WINDMÖLLER, C. C. A Questão do Mercúrio em Lâmpadas Fluorescentes. Química nova na escola. N. 28, Maio de 2008.

FARIAS, A. F. Avaliação do Conteúdo de mercúrio, metilmercúrio e outros elementos de interesse em peixes e em mostras de cabelos e dietas de pré-escolares da região Amazônica. Instituto de pesquisas energéticas e nucleares. (Tese) São Paulo, 2006.

FIORINI, M. Entrevista - Bruno Latour. Cult. Disponível em: $<$ https://revistacult.uol.com.br/home/entrevista-bruno-latour//>. Acesso em 18 out. 2019.

GERHARDT, T. E.; SILVEIRA D. T. [org] Métodos de pesquisa - UAB/UFRGS e pelo Curso de Graduação Tecnológica - Planejamento e Gestão para o Desenvolvimento Rural da SEAD/UFRGS. - Porto Alegre: Editora da UFRGS, 2009.

GIL, A.C. Métodos e técnicas de pesquisa social. - 6. ed. - São Paulo: Atlas, 2008. Disponível em: <https://ayanrafael.files.wordpress.com/2011/08/gil-a-cmc3a9todos-e-tc3a9cnicas-de-pesquisa-social.pdf > Acesso em: 25 de maio de 2020.

GIL, A. C. Como elaborar projetos de pesquisa. - $5^{\text {a }}$ ed. - São Paulo: Atlas. 2010.

GRISA, C.; SCHNEIDER S. (Org). Políticas públicas de desenvolvimento rural no Brasil. Porto Alegre: Editora da UFRGS, 2015. $624 \mathrm{p}$

INGOLD, T. Chega de etnografia! A Educação da atenção como propósito da antropologia. Educação (revista quadrimestral) Porto Alegre, v.39, n.3, p 4004 411, set-dez 2016.

INGOLD, T. Pare, olhe, escute! Um prefácio. Pontourbe. Revista do núcleo de antropologia urbana da USP. Ano 2, versão 3.o, juho de 2008.

KESSLER, R. The Minamata Convention on Mercury: A First Step Toward Protecting Future Generations.Environmental Health Perspectives. v.121, n.10, 2013, p. 304-308. Disponível em:<https://www.ncbi.nlm.nih.gov/pmc/articles/PMC3801463/>. Acesso em: 20 set. 2019.

LACERDA, L. D.; MALM, O. Contaminação por mercúrio em ecossistemas aquáticos: uma análise das áreas críticas. Estudos Avançados. v.22, n. 63, 2008, p. 173-190.

LATOUR, B. Ciência em ação: como seguir cientistas e engenheiros sociedade afora; tradução Ivone C. Bendedetti; revisão de tradução Jesus de Paula Assis. 2 ${ }^{\mathrm{a}}$ ed. São Paulo: Ed. Unesp, 2011.

LATOUR, B. Jamais fomos modernos: ensaio de antropologia simétrica. São Paulo: Editora 34, 2019 (4⿳亠丷厂 Edição) 
LATOUR, B. A esperança de Pandora: ensaio sobre a realidade dos estudos científicos/ Bruno Latour; tradução de Gilson César Cardoso de Souza. Bauru, SP: EDUSC, 2001.

MEDEIROS, Z.; VENTURA, P. C. S. Cultura tecnológica e redes sociotécnicas: um estudo sobre o portal da rede municipal de ensino de São Paulo* Educação e Pesquisa. vol.34 no.1 São Paulo Jan./Apr. 2008.

MÖLLERKE, R.O. Mercúrio, Arsênio e Colimetria como indicadores biológicos, na avaliação da qualidade dopescado artesanal do Lago Guaíba - Porto Alegre, Estado do Rio Grande do Sul, Brasil. 20 02. Tese (Faculdade de Medicina Veterinária) - Universidade Federal do Rio Grande do Sul, 2002.

MOMBACH, V. L. et al. O Estado da Arte na Reciclagem de Lâmpadas Fluorescentes No Brasil: Parte 1 Acta Ambiental Catarinense. v. 5. n. 1/2, jan./dez, 2008.

MORAES, M. A ciência como rede de atores: ressonâncias filosóficas. História, Ciências, Saúde-Manguinhos, Rio de Janeiro, vol. 11, n.2, p. 321333, mai./ago. 2004.

OGA, S. et al. Fundamentos da Toxicologia. 3.ed. São Paulo: Atheneu, 2008. QUEIROZ e MELO, M. F. A.; MORAES, M. O. A técnica como modo de existência: um diálogo entre as ideias de Latour e Simondon. Memorandum, 31, 276-297, 2016.

RAPOSO, C. Contaminação ambiental provocada pelo descarte não-controlado de lâmpadas de mercúrio no Brasil. Tese. Centro de Desenvolvimento da Tecnologia Nuclear/CDTN, Belo Horizonte, MG, Brasil, 2001.

SATO, M. \& CARVALHO I. C. M. (ORG.). Educação Ambiental: pesquisa e desafios. Porto Algere: Artmed, 2005.

SOUZA, W. B. Estudo teórico de mercúrio com grupos carboxílicos de substâncias húmicas. 2013. 151 f. Dissertação - Universidade Federal do Amazonas, Manaus, 2013. Disponível em: $<$ https://pubs.rsc.org/en/content/getauthorversionpdf/c4ra03594a >. Acesso em: 15 de nov. 2018. 